\title{
Use of levetiracetam in pediatric refractory status epilepticus
}

\author{
Shakya KN', Bhatta A², Phuyal S3, Yadav A $^{4}$
}

${ }^{1}$ Kashyap Narsingh Shakya, Professor; ${ }^{2}$ Anwesh Bhatta, Lecturer; ${ }^{3}$ Samjhana Phuyal Second year Resident; ${ }^{4}$ Arabindra Yadav, First year Resident; Department of Pediatrics, Kathmandu Medical College, Kathmandu, Nepal.

\begin{abstract}
Refractory status epilepticus, with persistence of seizures despite initial intravenous benzodiazepine and one secondline intravenous antiepileptic drug occurs in nine percent to $44 \%$ of the patients with status epilepticus. Aggressive treatment is needed to control such seizures with drug refractoriness. A case of a 2-year-old boy treated with intravenous levetiracetam with cessation of seizures, averting the need for general anesthesia is reported. Option of using levetiracetam in refractory status epilepticus is suggested.
\end{abstract}

Key words: Levetiracetam; Antiepileptic drug; Pediatric refractory seizure,

DOI: https://doi.org/10.3126/jkmc.v8i1.25268

\section{INTRODUCTION}

$\mathrm{R}$ efractory status epilepticus (RSE) occurs when seizures persist despite administration of one first-line medication (intravenous (I/V) benzodiazepine) and one second-line medication (I/V antiepileptic drug $)^{1}$. Nine percent to $44 \%$ of patients with Status Epilepticus (SE) have RSE ${ }^{2-4}$. It is associated with increased hospital length of stay and functional disability. When the standard, initial treatment fails to control the status the patient requires additional, more aggressive treatment ${ }^{5}$. We report here a case of refractory status epiepticus in a 2-year-old boy treated with intravenous Levetiracetam (LEV) with cessation of seizure averting the need for general anesthesia.

\section{THE CASE}

A 2 years old boy was admitted to the Pediatric Intensive Care Unit (PICU) with history of recurrent involuntary movements since one week. He had blinking of eyes, upwards rolling of eye balls, stiffening and jerky movements of bilateral limbs lasting for 3-5 minutes and recurring every 45 to 60 minutes without regaining full responsiveness in between the episodes. During this period he was attended at a local hospital where

Address for correspondence

Dr. Kashyap Narsingh Shakya, Professor,

Department of Pediatrics

Kathmandu Medical College, Sinamangal, Kathmandu

E-mail: shakyakashyap@yahoo.com
$\mathrm{I} / \mathrm{V}$ injections of anti-seizure drugs administered failed to control the involuntary movements. Subsequently, he was brought to Kathmandu Medical College Teaching Hospital (KMCTH) for further management. After admission in the PICU, he was given intravenous midazolam in repeated doses but the medication did not lead to cessation of seizure. He was then given loading doses of phenytoin, valproate and later I/V midazolam infusion consecutively, with only partial control of seizures.

Pending reports of investigations, I/V doses of mannitol, ceftriaxone and acyclovir were started. I/V LEV was started on day four of PICU admission as loading dose $50 \mathrm{mg} / \mathrm{kg}$ followed by maintenance dose. The seizures abated progressively and stopped and did not recur for $24 \mathrm{hr}$ enabling other anti-seizure drugs to be rapidly withdrawn. The child's Glasgow Coma Scale (GCS) ranged between 12 and 13. LEV (oral) was then continued through NG tube. He was shifted to the intermediary room, where he continued to remain stable and seizure free. He was transferred to the ward and discharged on day 16 on oral LEV. The child was reevaluated at follow-up visit two weeks later and was found to be fully interactive and playful without recurrence of seizures or any obvious neurological deficit.

\section{DISCUSSION}

LEV is one of the newest Anti-Epileptic Drugs (AEDs) which was approved by Food and Drug Administration (FDA) in $1999^{6,7}$. It binds to synaptic vesicle protein 
SV2A which is related to modulation of synaptic vesicle exocytosis and neurotransmitter release ${ }^{8}$. Animal models show that the affinity for SV2A is associated with protection against seizures ${ }^{9}$. Initially used as adjunctive therapy in partial seizures, it is now, increasingly proving to be a very useful drug in the treatment of epilepsy. It has been successfully used in adults as initial monotherapy ${ }^{10}$ as well as in the management of $\mathrm{SE}$, refractory and super-refractory SE with successful control of seizures ${ }^{11,12}$. It was used in pediatric cases of refractory SE with similar results ${ }^{13}$. In a comparative study in children, it was reported as effective as valproate and safer in the control of refractory $\mathrm{SE}^{13}$. Review of literature shows that use of LEV is considered safe and effective in children with refractory $\mathrm{SE}^{13-15}$. In a report of two years' experience with this drug in $\mathrm{SE}$, no severe adverse reactions were observed ${ }^{16}$. Use of $L E V$ or valproic acid has been proposed as a second step in managing SE after benzodiazepines and phenytoin as initial steps ${ }^{17}$. In our patient, control of seizure with initial I/V diazepam had failed elsewhere, before transfer to PICU. Subsequently, repeated doses of I/V midazolam as well as loading doses of phenytoin, valproate and midazolam infusion

\section{REFERENCES}

1. Holtkamp M, Othman J, Buchheim K, Meierkord $\mathrm{H}$. Predictors and prognosis of refractory status epilepticus treated in a neurological intensive care unit. Journal of Neurology, Neurosurgery \& Psychiatry. 2005; 76(4):534-39 www.ncbi.nlm.nih. gov/pubmed/15774441 [DOI]

2. Chin RF, Neville BG, Scott RC. A systematic review of epidemiology of status epilepticus. Eur J Neurol. 2004;11:800-10 https://www.ncbi.nlm.nih.gov/ pubmed/15667410 [PubMed]

3. Mayer SA, Claasen J, Lokin J, Mendelson F, Dennis LJ, Fitzsimmons BF. Refractory status epilepticus: frequency, risk factor and impact on outcome. Arch Neurol. 2002;59:205-10. https://www.ncbi.nlm.nih. gov/pubmed/11843690 [PubMed]

4. Marawar R, Basha M, Mahulikar A, Desai A, Suchdev K, Shah A. Updates in Refractory Status Epilepticus. Hindawi Critical Care Research and Practice. 2018;Volume 2018:1-19 Article ID 9768949, https:// doi.org/10.1155/2018/976894 [DOI]

5. Lowenstein DH.The Management of RefractoryStatus Epilepticus: An Update Epilepsia 2006; 47(s1):35-40. https://doi.org/10.1111/j.1528-1167.2006.00658. [DOI]

6. 6.6. Anonymous (1999). Drugs@FDA: FDA Approved Drug Products USA https://www.accessdata.fda. were unsuccessful in controlling the seizures. When LEV was available for I/V injection and bolus dose was started in our patient there was complete cessation of seizures without recurrence. No adverse effect of the drug was noted during the treatment and on follow-up visit two weeks later. Treatment was changed to oral LEV monotherapy, before discharge from the hospital.

Although, after initial benzodiazepines, phenytoin and valproate are used as standard second-line therapy in the control of SE in children ${ }^{18-21}$, I/V LEV should be considered as an effective and safe alternative treatment, prior to use of general anesthtics for the control of refractory SE in children ${ }^{15,22}$. Our experience with the present case has supported this option. A drawback in our set up was the unavailability of continuous EEG monitoring which is considered crucial for management of $\mathrm{SE}^{23}$.

\section{CONCLUSION}

General anesthesia with ventilatory and hemodynamic supports is needed to control seizure unresponsive to first and second line drugs; intravenous levetiracetam should be considered as an option.

gov/scripts/cder/daf/index.cfm?event=BasicSearch. process [DOI]

7. CenterWatch. List of FDA approved drugs for neurology: Approved in 1999. Washington: USA; c1995-2018. https://www.centerwatch.com/druginformation/fda-approved-drugs/therapeuticarea/10/neurology [DOI]

8. Wright C, Downing J, Mungall D, et al. Clinical pharmacology and pharmacokinetics of levetiracetam. Front Neurol. 2013;4:192. doi:10.3389/ fneur.2013.00192 https://www.researchgate.net/ publication/259450347_Clinical_Pharmacology_ and_Pharmacokinetics_of_Levetiracetam [DOI]

9. Delanty N, Jones J, Tonner F. Adjunctive levetriacetam in children, adolescents, and adults with primary generalized seizures: open-label, noncomparative, multicenter, long-term follow-up study. Epilepsia (2012) 53:111-910.1111/j.15281167.2011.03300.x [PubMed]

10. Abou-Khalil B. Levetiracetam in the treatment of epilepsy. Neuropsychiatr Dis Treat. 2008;4(3):507-23 [PubMed]

11. Stephen L J, Kelly K, Parker P, Brodie MJ. Levetiracetam monotherapy-Outcomes from an epilepsy clinic. Seizure 2011; 20:554-57. [DOI]

12. Patel NC, Landan IR, Levin J, Szaflarski J, Wilner AN. The use of levetiracetam in refractory status 
epilepticus. Seizure. 2006;15(3):137-41[PubMed]

13. Işgüder $R$, Güzel $O$, Ceylan $G$, Yılmaz $U, A$ ğın $H$. A Comparison of Intravenous Levetiracetam and Valproate for the Treatment of Refractory Status Epilepticus in Children. Journal of Child Neurology. 2016;31(9):1120-26. [DOI]

14. Mishra D, Sharma S, Sankhyan N, Konanki $R$, Kamate $M$, et al. Consensus Guidelines on Management of Childhood Convulsive Status Epilepticus. Indian Pediatr. 2014;51:975-90. https:// www.indianpediatrics.net/dec2014/dec-975-990. html [PubMed]

15. Kim JS, Lee JH, Ryu HW, Lim BC. Effectiveness of IntravenousLevetiracetamasanAdjunctiveTreatment in Pediatric Refractory Status Epilepticus. Pediatric Emergency Care. 2014;30(8):525-8. https://www.ncbi. nlm.nih.gov/pubmed/25062293 [DOI]

16. Eue S, Grumbt M, Müller M, Schulze A. Two years of experience in the treatment of status epilepticus with intravenous levetiracetam. Epilepsy \& Behavior. 2009;15(4):467-46. [DOI]

17. Abend NS, Dlugos DJ. Treatment of Refractory Status Epilepticus: Literature Review and a Proposed Protocol. Pediatric Neurology. 2008;38(6):37790. https://www.mc.vanderbilt.edu/documents/ neurology/files/Status\%20Epilepticus_lit_review. pdf [DOI]

18. Abend NS, Loddenkemper T. Management of pediatric status epilepticus. Current treatment options in neurology. 2014;16(7):301. https://www. ncbi.nlm.nih.gov/pmc/articles/PMC4110742/ [DOI]

19. Auab CC, Brancoc RG, Taskerad RC. Management protocols for status epilepticus in the pediatric emergency room: systematic review article. Jornal de Pediatria. 2017;93(1):84-94. https://doi. org/10.1016/j.jped.2017.08.004pen [DOI]

20. Poblete R, Sung G. Status Epilepticus and Beyond: A Clinical Review of Status Epilepticus and an Update on Current Management Strategies in Super-refractory Status Epilepticus. Korean J Crit Care Med. 2017;2:89-105 / https://doi.org/10.4266/ kjccm.2017.00252

19. GlauserT, Shinnar S, Gloss D, Alldredge B, Arya R, et al. Evidence-Based Guideline: Treatment of Convulsive Status Epilepticus in Children and Adults: Report of the Guideline Committee of the American Epilepsy Society. Epilepsy Curr. 2016;16(1):48-61. http://www. epilepsycurrents.org/doi/full/10.5698/1535-759716.1.48 [DOI]

22. Hirsch L J. Levitating Levetiracetam's Status for Status Epilepticus Epilepsy Curr. 2008;8(5):125-26. doi: 10.1111/j.1535-7511.2008.00266 https://www. ncbi.nlm.nih.gov/pmc/articles/PMC2566612/ [DOI]

23. Bleck TP. Status epilepticus and the use of continuous EEG monitoring in the intensive care unit. Continuum (Minneap Minn). 2012;18(3):560-78. doi: 10.1212/01. CON.0000415428.61277.90. https://www.ncbi.nlm. nih.gov/pubmed/22810249 [DOI] 